\title{
Terodiline with bladder retraining for treating detrusor instability in elderly people
}

\author{
Penelope A Wiseman, James Malone-Lee, G S Rai
}

\begin{abstract}
Objective-To compare terodiline with bladder retraining against placebo with bladder retraining in the treatment of detrusor instability in frail elderly patients.
\end{abstract}

Design-Randomised, double blind, parallel group study. Treatment lasted for six weeks. Frequency of micturition and episodes of incontinence recorded on diary chart by patients.

Setting-Incontinence clinic and a geriatric day hospital at two teaching hospitals.

Patients -37 frail but ambulant patients, mean (range) age $80.4(70-89)$ years with urinary frequency and urge incontinence, due to detrusor instability. Two patients withdrew before the first assessment (one in each group) and one could not complete the diary chart (placebo group).

Interventions -19 patients received bladder retraining and terodiline $25 \mathrm{mg}$ daily and 18 bladder retraining and placebo.

Main outcome measures-Change in urinary frequency and number of episodes of incontinence after six weeks' treatment. Patient's subjective evaluation of symptoms.

Results-Little difference was found in the results of treatment with terodiline and placebo. The change in episodes of incontinence per 24 hours was no different in the two groups $(95 \%$ confidence interval -0.6 to $1.2 ; p=0.75$ ) and the difference between treatments in the change in frequency of micturition per 24 hours $(-0.2)$ was not significant $(-1 \cdot 1$ to $1 \cdot 2$; $\mathbf{p}=\mathbf{0} \cdot 76$ ). Ten patients taking terodiline thought they had improved compared with seven receiving placebo; this difference was not significant.

Conclusion-Although the number of patients in each group was small and may have been insufficient to detect a drug effect, the possible benefit of terodiline is likely to be small.

\section{Introduction}

Detrusor instability is a common cause of urinary incontinence in elderly people. Current popular methods of treatment include bladder retraining or drugs (such as terodiline, imipramine, and oxybutynin), or both. Good clinical trial data are lacking to guide our choice of appropriate treatment.

Terodiline has antimuscarinic and calcium antagonistic properties. Both actions may block detrusor contractions in vitro and in vivo.' The drug is theoretically attractive as it has fewer antinicotinic properties than other antimuscarinics and may induce fewer side effects than would effective doses of other antimuscarinic and calcium antagonistic drugs.' Terodiline is now being prescribed widely for the treatment of urinary incontinence, notably by general practitioners. We describe a placebo controlled trial of the drug in elderly people, which examines the drug's efficacy and safety.

Correspondence to: Dr James Malone-Lee, $\mathrm{St}$ Pancras Hospital, London NW1 0PE.

\section{Patients and methods}

We performed a randomised, double blind, parallel group study. The study consisted of a run in period of seven days (week 0 ) followed by a treatment period of six weeks. Patients were randomised to receive terodiline $25 \mathrm{mg}$ each night or placebo. The dose of $25 \mathrm{mg}$ was the manufacturer's recommended dose in elderly patients on the basis of kinetic studies (Kabi, Stockholm, personal communication). ${ }^{3}$ All patients were instructed in bladder retraining at the start of treatment and at fortnightly home visits throughout the treatment period. They were asked to try and delay bladder emptying for as long as possible whenever they experienced the need to pass urine. We thought that it was unethical for the placebo group to receive no form of treatment, and it made clinical sense to compare a drug with another proved treatment. ${ }^{4}$

Outpatients of either sex aged over 70 with symptoms of urinary frequency and urge incontinence caused by detrusor instability were recruited. Patients had to be mobile and able to use a toilet or commode independently, able to understand and complete a bladder diary chart properly, and able to give informed consent. Patients taking diuretics were included only if the dose could remain constant throughout the study. We excluded patients who had had urinary infections during the previous four weeks; women with bladder neck prolapse; and patients with severe liver or renal disease, uncontrolled diabetes mellitus, glaucoma, or other contraindications to antimuscarinic treatment. We also excluded those taking other antimuscarinic drugs, calcium channel blockers, and non-steroidal anti-inflammatory drugs as these all affect the bladder. The study was approved by the local ethical commitees, and all patients gave a witnessed written consent.

Before patients were included in the study a neurological and (in women) gynaecological examination was performed and weight, height, blood pressure, and heart rate were measured. We confirmed detrusor instability by computed cystometry using criteria defined by the International Continence Society. ${ }^{56} \mathrm{We}$ measured baseline haemoglobin concentration, packed cell volume, white cell and platelet count, aspartate transaminase and alkaline phosphatase activities, serum creatinine and albumin concentrations, and serum terodiline concentration. A catheter specimen of urine was cultured. Patients completed a bladder diary chart by recording with a tick, to the nearest hour, each micturition and each incontinence episode. The chart was completed for seven days at run in (week 0 ) and collected.

Terodiline tablets containing $12.5 \mathrm{mg}$ terodiline hydrochloride and matching placebo were used. The random sequence was determined by the suppliers when the drug was packed, and the tablets were allocated to patients blind in order of their inclusion in the study.

After entering the study each patient was visited at home on days 14,28 , and 42 to check for compliance and to inquire about adverse reactions, in the event of which the dose was reduced to $12.5 \mathrm{mg}$ a day. Patients' subjective responses were recorded on a ranked ordinal scale as improved, unchanged, or worse. On days 28 and 42 further bladder charts, kept during the preceding week, were collected. The mean daily number of micturitions and episodes of incontinence for weeks 4 and 6 were calculated from these charts. 
Blood samples were taken to measure serum terodiline concentrations and haematological and biochemical parameters and a midstream specimen of urine cultured.

\section{STATISTICAL METHODS}

An initial sample size of 40 patients was calculated on the assumption that $35 \%$ of these patients would improve on placebo and $65 \%$ on terodiline. This calculation was incorrect, but including bladder retraining casts doubt on the validity of the assumptions anyway. The effects of sample size are considered in the discussion. The analysis is presented in terms of micturitions and incontinence episodes and associated confidence intervals. We used non-parametric methods to analyse treatment effects regarding the numbers of micturitions and incontinence episodes during the day, during the night, and over 24 hours: the MannWhitney $U$ test for the difference between two population medians was used to examine the difference in changes between the two groups. We also calculated the $95 \%$ confidence intervals of the difference between medians of each group. Calculations were performed with the statistical software package Minitab. ${ }^{7}$ The subjective evaluation of treatment was analysed by using the $\chi^{2}$ test with Yates's correction.

Results

PATIENTS

Thirty seven patients (mean age $80 \cdot 4$, range 70 to 89 ) entered the study: 19 were randomised to receive terodiline and 18 placebo. Insufficient data were available on three patients. Two patients withdrew their consent before the first assessment: one suspected an adverse reaction (placebo group) and the other refused to continue taking tablets (treatment group) and therefore provided incomplete data. Another patient proved unable to complete the diary chart and consequently provided no data (placebo group). Two patients developed urinary tract infections during the study (both in placebo group) but were included in the analysis on an "intention to treat" principle. In consequence we analysed data on 16 patients in the placebo group and 18 patients in the terodiline group.

Table I shows the characteristics of the two groups. The urodynamic data are given in terms of medians and ranges because they are skewed. Patients were well matched other than for weight, and had similar cognitive and functional ability.

\section{EFFICACY ANALYSIS}

The figure shows the changes in average frequency of micturition and incontinence episodes per 24 hours from week 0 to week 6 of treatment for each patient;

TABLE I-Characteristics of patients in two groups on inclusion to study. Values are median (range) unless stated otherwise

\begin{tabular}{|c|c|c|}
\hline & Terodiline group & Placebo group \\
\hline Sex (female/male) & $16 / 2$ & $14 / 2$ \\
\hline Mean (range) age (years) & $80 \cdot 3(73$ to 89$)$ & $80 \cdot 5(70$ to 86$)$ \\
\hline Mean (SD) weight $(\mathrm{kg})$ & $66 \cdot 5(12 \cdot 1)$ & $60 \cdot 7(8 \cdot 4)$ \\
\hline Residual urine (ml) & $20(0$ to 160$)$ & $20(0$ to 200$)$ \\
\hline Bladder capacity $(\mathrm{ml})$ & $200(75$ to 501$)$ & $228(53$ to 500$)$ \\
\hline $\begin{array}{l}\text { Bladder volume at first } \\
\text { sensation }(\mathrm{ml})\end{array}$ & $112(24$ to 269$)$ & $125(33$ to 401$)$ \\
\hline $\begin{array}{l}\text { Detrusor pressure at first } \\
\text { sensation }(\mathrm{kPa})\end{array}$ & $1.47(0.09$ to $5 \cdot 1)$ & $1.47(0.74$ to 3.73$)$ \\
\hline No of patients taking diuretics & 3 & 4 \\
\hline \multicolumn{3}{|l|}{$\begin{array}{l}\text { Average No of micturitions } \\
\text { (interquartile range): }\end{array}$} \\
\hline During day & $6 \cdot 4(5 \cdot 1$ to $7 \cdot 8)$ & $5 \cdot 1(4 \cdot 8$ to $8 \cdot 5)$ \\
\hline During night & $1.75(1.1$ to $2 \cdot 2)$ & $1.35(1.0$ to $2 \cdot 6)$ \\
\hline Each $24 \mathrm{~h}$ & $8 \cdot 4(6.4$ to 9.5$)$ & $6 \cdot 75(5 \cdot 7$ to $11 \cdot 0)$ \\
\hline \multicolumn{3}{|c|}{$\begin{array}{l}\text { Average No of incontinence } \\
\text { episodes (interquartile range): }\end{array}$} \\
\hline During day & $2 \cdot 75(0.3$ to $3 \cdot 6)$ & $14(0$ to $2 \cdot 8)$ \\
\hline During night & $0.35(0$ to $1 \cdot 1)$ & $0.2(0$ to 0.6$)$ \\
\hline Each $24 \mathrm{~h}$ & $3 \cdot 25(0 \cdot 4$ to $4 \cdot 5)$ & $1 \cdot 85(0$ to $3 \cdot 4)$ \\
\hline
\end{tabular}

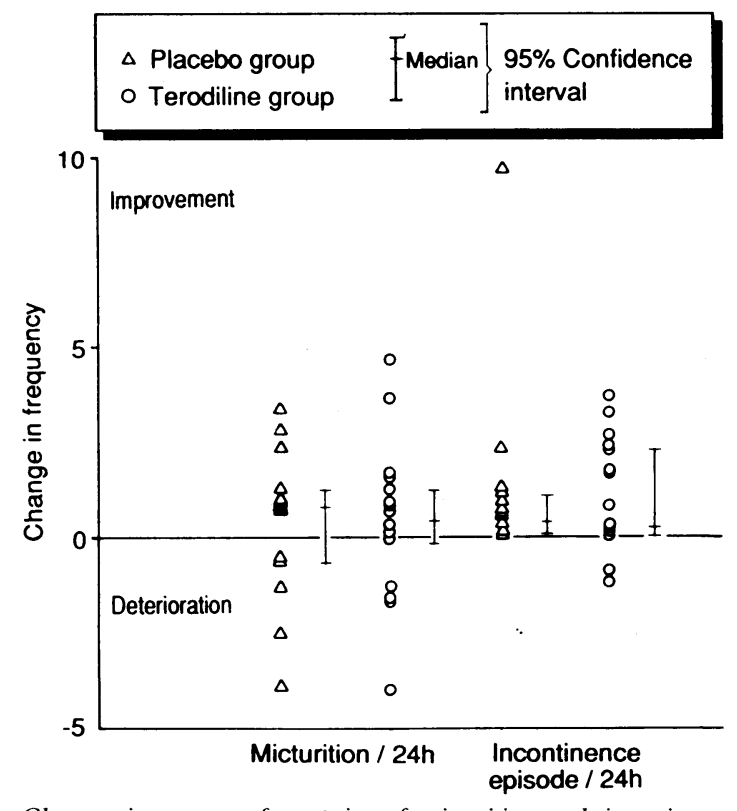

Changes in average frequercies of micturition and incontinence episodes between week 0 and week 6 of study

TABLE $\mathrm{II}-$ Median difference in change between terodiline and placebo groups for each parameter

\begin{tabular}{|c|c|c|c|}
\hline Variable & $\begin{array}{c}\text { Median difference } \\
\text { (95\% confidence interval) }\end{array}$ & W Value ${ }^{\star}$ & $\mathrm{p}$ Value \\
\hline Micturitions during day & $0.05(-1.0$ to 1.1$)$ & 310 & 0.89 \\
\hline Micturitions during night & $-0.15(-0.6$ to 0.4$)$ & 329 & 0.64 \\
\hline Micturitions each $24 \mathrm{~h}$ & $-0.2(-1 \cdot 1$ to $1 \cdot 2)$ & 270 & $0 \cdot 76$ \\
\hline Incontinence during day & $0.15(-0.5$ to 1.1$)$ & 294 & 0.64 \\
\hline Incontinence during night & $0(-0.2$ to 0.3$)$ & 287 & 0.80 \\
\hline Incontinence each $24 \mathrm{~h}$ & $0(-0.6$ to 1.2$)$ & 289 & 0.75 \\
\hline
\end{tabular}

${ }^{\star} \mathrm{W}$ is the statistic of the Mann-Whitney $\mathrm{U}$ test.

positive values indicate improvement. Overall, 22 patients recorded an improvement in their incontinence.

Table II shows the median difference in the change in frequency of micturition and incontinence episodes between the terodiline and placebo groups. The median frequencies of micturitions improved slightly in both groups, as did the frequencies of incontinence episodes, but no significant difference was found in these changes between the two groups.

Ten patients $(56 \%)$ taking terodiline and seven (44\%) taking placebo believed that they had improved by day 42 . The remainder thought that their condition was unchanged. The difference between the two groups was $12 \%$ ( $95 \%$ confidence interval $44 \%$ to $-22 \%)$; this difference was not significant $\left(\chi^{2}=0 \cdot 118\right.$, $\mathrm{df}=1 ; \mathrm{p}=0 \cdot 73$ ).

ASSESSMENT OF SAFETY AND TOLERANCE

Two patients developed side effects on terodiline (one oesophagitis, another a dry mouth). They continued in the study taking $12.5 \mathrm{mg}$ daily. There were no marked changes in blood pressure, heart rate, or haematological or biochemical variables. Concentrations of terodiline in the serum indicated good compliance, and all but two patients had concentrations in the expected range. The mean (SD) serum terodiline concentration was $547(416) \mu \mathrm{g} / \mathrm{l}$ after 28 days and 542 (427) $\mu \mathrm{g} / \mathrm{l}$ after 42 days. The patient who developed tolerable oesophagitis had concentrations of $405 \mu \mathrm{g} / 1$ and $235 \mu \mathrm{g} / \mathrm{l}$ after 28 and 42 days respectively, and the patient with a dry mouth had concentrations of $298 \mu \mathrm{g} / 1$ and $231 \mu \mathrm{g} / \mathrm{l}$ at these times.

\section{Discussion}

We believe that the improvement in incontinence in both groups can be attributed to bladder retraining, 
which is an accepted treatment for detrusor instability and that terodiline $25 \mathrm{mg}$ daily does not improve on its efficacy. The number of patients in the study, however, was small and may have been insufficient to detect a drug effect. We required very elderly, ambulant, and compliant patients for the trial to be confident of the accuracy of our outcome measures, and such patients are difficult to recruit.

Nevertheless it was a single centre study, and we recruited more patients than all other controlled trials of terodiline apart from one multicentre trial. ${ }^{8}$ We have found that multicentre studies conducted on elderly patients are particularly difficult to coordinate.

To detect a possible drug effect in a trial which includes bladder retraining 378 patients would be required (Kabi, United Kingdom, personal communication), which would be impracticable. Even though there was no significant difference between terodiline and placebo groups in frequency of micturition or incontinence episodes, any change might have achieved significance with more patients. The median improvements in micturition and incontinence are similar between treatment groups despite the fact that the terodiline group had, if anything, worse symptoms at run in and thus more potential for improvement. The upper end of the $95 \%$ confidence interval for the difference between the terodiline and placebo groups was around one micturition or incontinence episode during the day or per 24 hours. We therefore believe that even if terodiline with bladder retraining is better than placebo with bladder retraining the benefit is likely to be marginal.

Although the dose of terodiline was smaller than that recommended for younger patients and the incidence of side effects was lower than in other studies, $25 \mathrm{mg}$ daily is the recommended dose for elderly patients and produced steady state serum concentrations of the drug similar to those produced by larger doses in younger patients. ${ }^{34}$ Indeed, our patients' serum concentrations of the drug were higher than those in other terodiline studies. ${ }^{89}$ Because terodiline is a calcium channel blocker postural instability may develop in elderly patients given higher doses, and prescribing must be cautious. The half life of the drug in elderly patients is more than double that in younger patients, with a mean of about 130 hours, and this justifies a single dose regimen. ${ }^{3}$

The frequency of micturition did not change significantly in either group, perhaps because our patients recorded fairly mild urinary frequency. Nevertheless, their overall urinary symptoms were severe enough to warrant referral by general practitioners to an incontinence clinic or outpatient clinic. Patients may have underrecorded their urinary frequency, but this did at least apply to both groups throughout the study. Despite the fairly low run in values patients could have improved well above the level of the upper confidence interval.

In this type of study outcome is difficult to measure, but our experience in the incontinence clinic has shown that bladder diary charts remain the most reliable measure. Urodynamic parameters are often advocated as suitable objective measures, but several studies have shown that they correlate poorly with symptoms. ${ }^{910}$ More direct methods, such as weighing incontinence pads, pose major logistical problems. Ultimately what matters is how the patient perceives his or her condition, which is what is reflected in the charts.

In conclusion, we have not produced evidence to support the current belief that terodiline confers any additional benefit over bladder retraining in the treatment of detrusor instability in frail elderly patients.

This work was supported by Kabi, United Kingdom. We thank Brian Newman of University College, London, for statistical advice.

1 Rud T, Anderson KE, Boye N, Ulmsten U. Terodiline inhibition of human bladder contraction. Effects in vitro and in women with unstable bladders. ticta Pharmacologica et Toxicologica 1980;46(suppl 1):31-8.

2 Ulmsten U, Andersson KE. Drug treatment of the overactive detrusor. Acta Pharmacologica et Toxicologica 1980;46(suppl):7-10.

3 Hallen B, Magnusson A, Bogentoft S, Ekelund P. Single and multiple dose pharmacokinetics of terodiline in geriatric patients. Eur $\mathcal{f}$ Clin Pharmacol 1988;34:291-7.

4 Frewen WK. A reassessment of bladder training in detrusor dysfunction in the female. $B r \mathcal{F}$ Urol 1982;54:372-3.

5 Abrams P. Feneley R, Torrens M. Urodynamics. London: Springer-Verlag, 1983:110-2

6 Malone-Lee JG, Chapple CR. In: Coleridge-Smith PD, Scurr JE, eds. Medical applications of microcomputers. A critical reziew of the development of a software package for clinical urodynamics. London: Springer-Verlag, 1988:87-93.

7 Minitab Inc. Minitah release 7. Pennsylvania: Minitab Inc, 1989.

8 Peters DF. Terodiline in the treatment of urinary frequency and motor urge incontinence. A controlled multicentre trial. Scand $\mathcal{F}$ Urol Nephrol 1984;87: suppl : 21 - 33 .

9 Fischer-Rasmussen $W$. Evaluation of long-term safety and clinical benefit in women with urgency/urge incontinence. A multicentre study. Scand $\mathcal{F}$ Urol Wephrol 1984:87 (suppl:35:47.

10 Macfarlane J, Tolley D. The effect of terodiline on patients with detrusor instability. Scand f Urol Nephrol 1984;87 (suppl):51-4.

(Accepted 27 February 1991)

\section{Munchausen's syndrome and abnormalities on magnetic resonance imaging of the brain}

\author{
Service des Maladies du \\ Système Nerveux, Hôpital \\ Tenon, 75970 Paris Cedex \\ 20, France \\ Gilles Fénelon, MD, \\ neurologist \\ Florence Mahieux, MD, \\ neurologist \\ Alain Guillard, MD, professor \\ of neurology
}

\section{Service de Neurologie, Hôpital St Antoine, Paris \\ Etienne Roullet, MD,} neurologist

\section{Gilles Fénelon, Florence Mahieux, Etienne Roullet, Alain Guillard}

The possibility of "a real organic lesion from the past" in Munchausen's syndrome was pointed out by Asher in his classic article.' Cerebral damage was later mentioned in a few cases, and Barker suggested that it might provide an organic basis for the syndrome. ${ }^{2} \mathrm{We}$ report a typical case of Munchausen's syndrome in which magnetic resonance imaging of the brain showed abnormalities.

\section{Case report}

A 35 year old man was admitted to several hospitals in Paris on at least 13 occasions between July 1986 and
June 1988 under eight known identities. He allegedly had been treated for appendicular peritonitis, inguinal hernia, spontaneous or traumatic pneumothorax, or gastric or duodenal ulcer. He also gave a history of cataract, detached retina, or glaucoma and of alcoholism, cardiac arrhythmia, urinary infection, epilepsy, and diabetes and claimed an allergy to iodine preparations. He recounted a life full of various tragic events concerning his mother, children, and wife; he was evasive about other relatives and friends and gave different names of general practitioners, which were not in professional registers.

In most documented cases the patient presented to the emergency room, saying that he had just experienced a generalised seizure or a hypoglycaemic episode. Sometimes a "weakness" of the left arm and leg persisted for a few days, but neurological examination otherwise yielded normal results. He was once caught rubbing the thermometer to raise the temperature. On several occasions he asked for his "usual" treatment, either oral hypoglycaemic drugs or insulin (he would give the insulin's proprietary name and dose). Genuine hypoglycaemia ensued several times, but investigations failed to confirm diabetes. During 